\title{
ARTICLE
}

Clinical Study

\section{The effect of geriatric intervention in frail older patients receiving chemotherapy for colorectal cancer: a randomised trial (GERICO)}

\author{
Cecilia Margareta Lund (1D ${ }^{1,2,3}$, Kirsten Kjeldgaard Vistisen ${ }^{4}$, Anne Pries Olsen ${ }^{5}$, Pernille Bardal ${ }^{6}$, Martin Schultz ${ }^{1,2}$, \\ Troels Gammeltoft Dolin ${ }^{1,2}$, Finn Rønholt ${ }^{1}$, Julia Sidenius Johansen ${ }^{1,3,4}$ and Dorte Lisbeth Nielsen ${ }^{3,4}$
}

BACKGROUND: Older patients with colorectal cancer (CRC) experience chemotherapy dose reductions or discontinuation. Comprehensive geriatric assessment (CGA) predicts survival and chemotherapy completion in patients with cancer, but the benefit of geriatric interventions remains unexplored.

METHODS: The GERICO study is a randomised Phase 3 trial including patients $\geq 70$ years receiving adjuvant or first-line palliative chemotherapy for CRC. Vulnerable patients (G8 questionnaire $\leq 14$ points) were randomised 1:1 to CGA-based interventions or standard care, along with guideline-based chemotherapy. The primary outcome was chemotherapy completion without dose reductions or delays. Secondary outcomes were toxicity, survival and quality of life (QoL).

RESULTS: Of 142 patients, 58\% received adjuvant and $42 \%$ received first-line palliative chemotherapy. Interventions included medication changes (62\%), nutritional therapy (51\%) and physiotherapy (39\%). More interventional patients completed scheduled chemotherapy compared with controls ( $45 \%$ vs. $28 \%, P=0.0366)$. Severe toxicity occurred in $39 \%$ of controls and $28 \%$ of interventional patients $(P=0.156)$. QoL improved in interventional patients compared with controls with the decreased burden of illness $(P=0.048)$ and improved mobility $(P=0.008)$.

CONCLUSION: Geriatric interventions compared with standard care increased the number of older, vulnerable patients with CRC completing adjuvant chemotherapy, and may improve the burden of illness and mobility.

TRIAL REGISTRATION: ClinicalTrials.gov ID: NCT 02748811.

British Journal of Cancer (2021) 124:1949-1958; https://doi.org/10.1038/s41416-021-01367-0

\section{BACKGROUND}

Comprehensive geriatric assessment (CGA) in the trajectory of cancer care is recommended to improve treatment outcomes for older patients with cancer. ${ }^{1}$ As the incidence of cancer increases with age $^{2}$ and populations are getting older, ${ }^{3}$ the interest in CGA is increasing. ${ }^{4}$ Older patients are a heterogeneous group, ranging from fit to frail, with varying comorbidities and ability to tolerate chemotherapy. ${ }^{5}$ Thus, chronological age by itself should not be an exclusion criterion for adjuvant or palliative chemotherapy. ${ }^{6-8}$

Colorectal cancer (CRC) mortality has decreased during the last decade, although most markedly in younger patients. ${ }^{9,10}$ Adjuvant chemotherapy for 3-6 months after surgery for stage II/III colon cancer (CC) ${ }^{11-15}$ and rectal cancer ${ }^{16}$ improves disease-free survival (DFS) and overall survival (OS). Adjuvant treatment prolongs DFS in patients $\geq 70$ years, ${ }^{17}$ and OS is higher in CRC patients $>75$ years receiving adjuvant chemotherapy than in patients receiving no treatment. ${ }^{18-20}$ For patients with metastatic CRC, median survival is only $10-11$ months, $^{21}$ mainly due to comorbidity in older patients and patients with poor performance status (PS) who do not receive treatment.

CGA is a multidisciplinary evaluation of an older individual's comorbidity and medications, functional, social and nutritional status, physical performance and cognitive and emotional function. ${ }^{22,23}$ In a meta-analysis of randomised controlled trials (RCTs), CGA-based interventions during hospitalisation increased the likelihood of being alive and living at home 6 months after hospital discharge compared with standard care. ${ }^{24}$

In older patients with cancer, CGA can predict chemotherapy toxicity, morbidity and survival, ${ }^{25-28}$ and is recommended by the American Society of Clinical Oncology (ASCO). ${ }^{1}$ Geriatric assessment can predict survival in patients after CRC surgery ${ }^{29}$ and identify geriatric problems, leading to changes in chemotherapy-treatment strategy in up to $54 \%$ of patients. ${ }^{30}$ The G8 questionnaire is recommended as a sensitive screening tool ${ }^{31}$ that can predict survival and treatment-related complications. ${ }^{32}$ For patients with a G8 score $\leq 14$, full CGA is recommended. ${ }^{33}$

\footnotetext{
${ }^{1}$ Department of Medicine, Copenhagen University Hospital, Herlev and Gentofte, Copenhagen, Denmark; ${ }^{2}$ CopenAge, Copenhagen Center for Clinical Age Research, University of Copenhagen, Copenhagen, Denmark; ${ }^{3}$ Department of Clinical Medicine, Faculty of Health and Medical Sciences, Copenhagen University, Copenhagen, Denmark; ${ }^{4}$ Department of Oncology, Copenhagen University Hospital, Herlev and Gentofte Hospital, Copenhagen, Denmark; ${ }^{5}$ Department of Physiotherapy and Occupational Therapy, Copenhagen University Hospital, Herlev and Gentofte, Copenhagen, Denmark and ${ }^{6}$ Nutritional and Dietetic Research Unit, Copenhagen University Hospital, Herlev and Gentofte, Copenhagen, Denmark

Correspondence: Cecilia Margareta Lund (Cecilia.margareta.lund.01@regionh.dk)
} 
The aim of this study was to investigate whether CGA-based interventions in vulnerable older patients with CRC could enhance the number of patients completing scheduled chemotherapy.

\section{MATERIALS AND METHODS}

\section{Study design}

Phase 3 RCT comparing CGA-based interventions with standard care in vulnerable, older patients undergoing chemotherapy for CRC. ${ }^{34}$

\section{Setting}

The study was conducted at Departments of Oncology and Medicine, Copenhagen University Hospital, Herlev and Gentofte and Nordsjællands Hospital, Denmark.

\section{Participants}

Inclusion criteria. Patients $\geq 70$ years with stage II-IV CRC referred to the Department of Oncology for treatment with the adjuvant or first-line palliative/downstaging chemotherapy, a life expectancy $\geq 3$ months and a ECOG (Eastern Cooperative Oncology Group) PS of $0-2,{ }^{35}$ and assessed as vulnerable using the $\mathrm{G} 8$ questionnaire $(\mathrm{G} 8 \leq 14){ }^{36}$ All patients gave signed informed consent. Exclusion criteria: co-existing with other cancer within 5 years and participating in pharmaceutical trials.

The study was primarily designed to include patients receiving adjuvant chemotherapy after surgery for primary CRC. Fewer vulnerable patients than expected were offered or accepted chemotherapy, and fewer than expected accepted participating in a clinical trial ( $25 \%$ non-participants). Therefore, inclusion criteria were changed after 1 year to also include patients receiving downstaging, first-line palliative chemotherapy and adjuvant chemotherapy after surgical resection of metastatic CRC. Inclusion at Nordsjællands Hospital was low and closed after the inclusion of four participants.

\section{Randomisation}

The participants were randomised 1:1 to CGA-based interventions or standard care. Patients were stratified after PS $0-1$ vs. 2 and adjuvant vs. palliative/downstaging chemotherapy.

\section{Interventions}

Oncological treatment. All patients received standard treatment (Supplementary Table S1) consisting of 3-6 months of adjuvant chemotherapy ${ }^{15}$ or first-line palliative/downstaging chemotherapy with various duration until disease progression (CT scan every 3 months), surgery, change in treatment or end of treatment due to severe adverse events (AE). The standard dose was based on body surface area (BSA), with a possible $25 \%$ primary dose reduction if concerns of toxicity at the first oncological assessment.

CGA for the intervention group. Patients in the intervention group received CGA at the start of chemotherapy, if possible before the start of treatment, but otherwise up to a few days after chemotherapy start. The CGA included medication review, assessment of comorbidity, psycho-cognitive function and nutritional, functional and physical status with appropriate interventions, including referral to a dietitian and physical exercise programme (for CGA and implemented interventions see Table 1 and Supplementary Material). CGA-based interventions were followed up after 2 months or more frequently if needed.

Co-existing health problems among controls were assessed by either an oncologist or general practitioner.

Data collection, measures and outcomes

Collected data included demographics, comorbidities, medication, date of diagnosis, recurrence, progression and survival. Received chemotherapy, delays, AE (European Organization for Research and Treatment Cancer (EORTC) Common Terminology Criteria (CTC) version 4.0), weight and PS (including self-reported PS) were registered for all patients at every treatment cycle. For patients in the control group, information about weight loss or functional decline prior to chemotherapy was collected retrospectively from medical charts.

The patients participated in the study until planned treatment ended or occurrence of disease recurrence (adjuvant group), disease progression (palliative group), resection of metastases (downstaging group) or treatment stopped due to AEs or poor PS. EORTC quality-of-life (QoL) questionnaires (QLQ) QLQ C $30^{37}$ and QLQ ELD-14 ${ }^{38}$ were completed in all patients prior to randomisation, at the oncological appointment prior to chemotherapy after 2 months, and at the end of treatment (at the oncological appointment prior to the last cycle of adjuvant chemotherapy ( 3 or 6 months) or in case of progression (palliative setting)) or at early discontinuation. QoL domains range from zero to 100 , where a high score indicates a higher function for functional scores and a higher grade of symptom burden for symptom domains. For patients in the exercise programme, a physical test battery, including 30-s chair-stand test (CST), 30-s arm-curl test, leg-press maximum weight and climbing-stair test, was performed before and after 24 exercise sessions.

Blinding of oncologists was not possible, as the results of the geriatric assessment were included in the patients' medical charts.

The primary outcome was the completion of planned chemotherapy without later dose modifications or delays (oxaliplatin not included). The primary outcome was assessed by a blinded oncologist. Secondary outcomes were dose reductions, treatment delays, adverse events and prognosis (DFS, PFS, and OS and CRC mortality).

\section{Statistical power and analyses}

Planned treatment is usually completed in $\sim 50 \%$ of patients. ${ }^{19}$ No prior study has assessed the effect of the geriatric intervention on chemotherapy completion, but completion was assumed to increase to $75 \%$ after the geriatric intervention. With 140 patients included, such an increase would be detected with a probability (power) of $87 \%$ at a $5 \%$ significance level.

Categorical variables were analysed using a chi-square test. The result of the exercise programme was analysed with a paired sampled $t$ test. Dose intensity was defined as a cumulative given dose compared to a standardised total dose per week, and differences between the two groups were analysed with the Wilcoxon test.

Baseline QoL data were presented as means and standard deviations, and differences in mean change over time between the groups were analysed using the Wilcoxon test.

DFS was defined as the time from randomisation to disease recurrence or death, PFS as time from randomisation to disease progression or death and OS as time from randomisation to death of any cause. Survival was estimated with the Kaplan-Meier estimator and compared with a log-rank test as hazard ratios (HRs) and $95 \%$ confidence intervals (Cls).

All analyses were performed on complete cases only. All statistical analyses were performed using the statistical software package $R$, version $3.5 .2^{39}$, with a significance level of $5 \%$.

\section{RESULTS}

From April 2015 to September 2019, 484 patients were assessed for eligibility (Fig. 1). In total, 54 patients did not meet inclusion criteria, since they were found to be fit and not vulnerable according to the $\mathrm{G} 8$ screening $(n=129)$ or the patients did not receive chemotherapy $(n=121)$. Fifty-four patients did not want to participate, and 12 patients were excluded due to other coexisting cancer or other reasons $(n=15)$. Of the 153 patients 


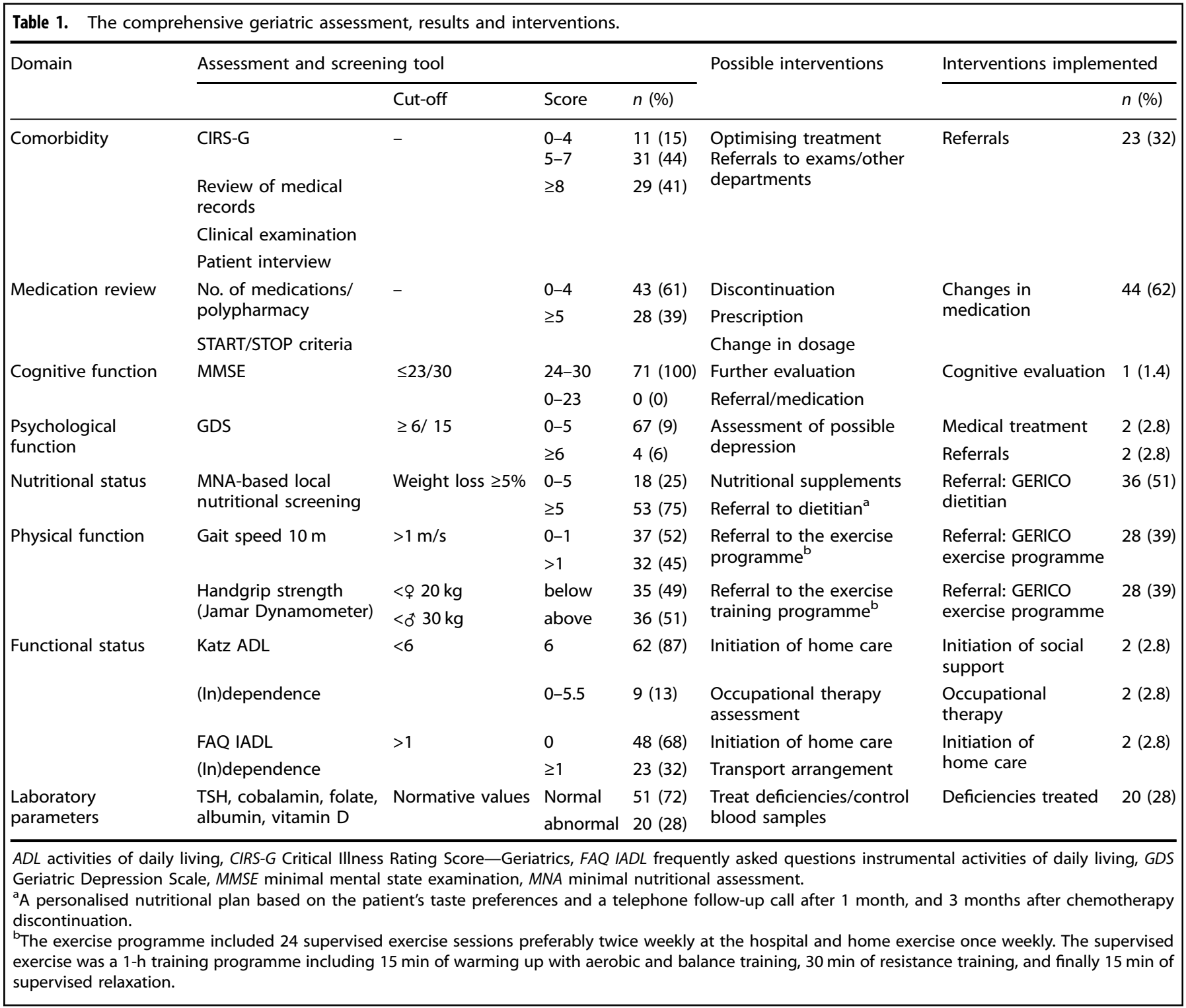

included, 11 patients were later excluded (withdrawal of consents $(n=2)$, treatment for coexisting cancer $(n=2)$, patients did not start chemotherapy $(n=4)$ and patients were hospitalised due to toxicity and discontinued chemotherapy prior to CGA $(n=3))$. For baseline characteristics of the 142 included patients, see Table 2 . Due to the heterogeneity caused by different treatment settings, analyses were performed in all patients and in two subgroups: patients who received adjuvant treatment after surgery for primary non-metastatic CRC $(n=77$, intervention group (I) $(n=$ $40)$, control group (C) $(n=37))$, and patients who received palliative treatment for metastatic disease (no downstaging treatment) $(n=44, \mathrm{I} \quad(n=22), \mathrm{C}(n=22))$. Patients receiving chemotherapy after resection of metastases $(n=15)$ and patients who had received downstaging chemotherapy $(n=6)$ were not included in sub-group analyses.

Geriatric interventions and quality of life Interventions were needed in $92 \%$ of patients in the intervention group ( $88 \%$ of patients in the adjuvant group and in $100 \%$ of palliative patients). The most frequently implemented interventions were changes in medication $(62 \%)$, nutritional therapy $(51 \%)$ and exercise (39\%) (Table 1). The need for nutritional therapy and exercise was most pronounced in the palliative group $(64 \%$ vs. $43 \%$ and $50 \%$ vs. $38 \%$ ). None of the patients had cognitive impairment (mini-mental state examination (MMSE) below the cut-off <24) and $6 \%$ had possible depression.

Physiotherapy. Fifty-one of 71 patients $(72 \%)$ in the intervention group performed below cut-off in at least one of the physical screenings and were considered in need of physiotherapy. Of the 28 patients who accepted referral to the exercise programme, 24 agreed to postinterventional tests. The exercise programme was found to significantly increase physical strength in all four tests (Supplementary Table S2), at a level known to be a clinically important difference. ${ }^{40}$

Self-reported physical decline assessed by ECOG PS was seen in both groups $(25 \%$ vs. $35 \%, P=0.201)$. In the adjuvant setting, there was no difference ( $28 \%$ vs. $32 \%, P=0.637)$, but in the palliative group, fewer interventional patients experienced a physical decline $(18 \%$ vs. $50 \%, P=0.026)$. Sixteen $(23 \%)$ control patients were referred to municipal physiotherapy. Patients receiving therapy (intervention and controls combined) had less decline in PS than patients deemed in need of physiotherapy, but not exercising $(18.5 \%$ vs. $31.8 \%, P=0.128)$ with a significant 
difference among adjuvant patients ( $10.3 \%$ vs. $34.6 \%, P=0.048)$. Also when analysing changes in QoL from start to 2 months, mobility was significantly worsened in controls compared with interventional patients during the study period $(-8.39$ standard deviation (SD) 24.69 vs. -0.43 SD 17.46, $P=0.008$ ) (Supplementary Table S3), and burden of illness decreased more in the intervention than in the control group (-5.13SD 25.68 vs. 4.67 SD 20.77, $P=0.048$ ).

Nutritional therapy. Fifty-three (75\%) patients in the intervention group had weight loss $>5 \%$ prior to chemotherapy and were considered at risk of malnutrition, and 36 patients (51\%) accepted dietitian referral. Of patients treated with palliative chemotherapy, $23 \%$ refused nutritional consultation. Among controls, 45 patients $(63 \%)$ were at risk of malnutrition and 8 patients $(11 \%)$ were referred to a dietitian.

Further significant weight loss, defined as $>2.5 \%$ during treatment ${ }^{41}$, was seen in $15 \%$ of patients in the intervention group and in $24 \%$ of controls $(P=0.206)$.

Primary endpoint (completion of planned chemotherapy) More patients in the intervention group completed planned chemotherapy without further dose reductions or delays than in the control group ( $45 \%$ vs. $28 \%, P=0.0366)$ (Table 3$)$. The difference was most prominent in patients in the adjuvant setting ( $P=0.0097)$, whereas no significant difference was seen in the palliative group $(P=0.751)$. Associations between baseline characteristics and the effect of the geriatric intervention on completion of scheduled chemotherapy are shown in Fig. 2 . The beneficial effect of CGA was mainly found in patients with G8 score $\leq 11$ (odds ratio OR 3.76, 95\% confidence interval $(\mathrm{Cl})$ 1.19-13.45).

Dose reductions, delays and received chemotherapy

Start doses were reduced in $60 \%$ of all patients with no difference between the intervention and control group (Table 3). Secondary dose reductions occurred more rarely in the intervention group ( $28 \%$ vs. $45 \%, P=0.037$ ). More patients in the intervention group received the planned dose in all given cycles of chemotherapy ( $65 \%$ vs. $42 \%, P=0.007)$. There were no differences between the two groups regarding the received median dose intensity or a number of cycles for capecitabine, 5-fluorouracil, oxaliplatin or irinotecan throughout the treatment. No difference was found in median treatment duration and delays occurred equally in both.

Adverse events and hospitalisation

In total, $28 \%$ of patients in the intervention group experienced toxicity grade 3 or more compared with $39 \%$ among controls ( $P=$ $0.156)$. Most frequently, grade $3+$ adverse events were infections $(n=11)$, cardiotoxicity $(n=10)$ and fatigue $(n=8)$. For all grade AEs, see Table 4. Hospitalisation during chemotherapy occurred with equal frequency in both groups (30\% vs. $32 \%, P=0.857)$ and $20 \%$ in the intervention group and $30 \%$ in the control group discontinued chemotherapy due to toxicity $(P=0.173)$.

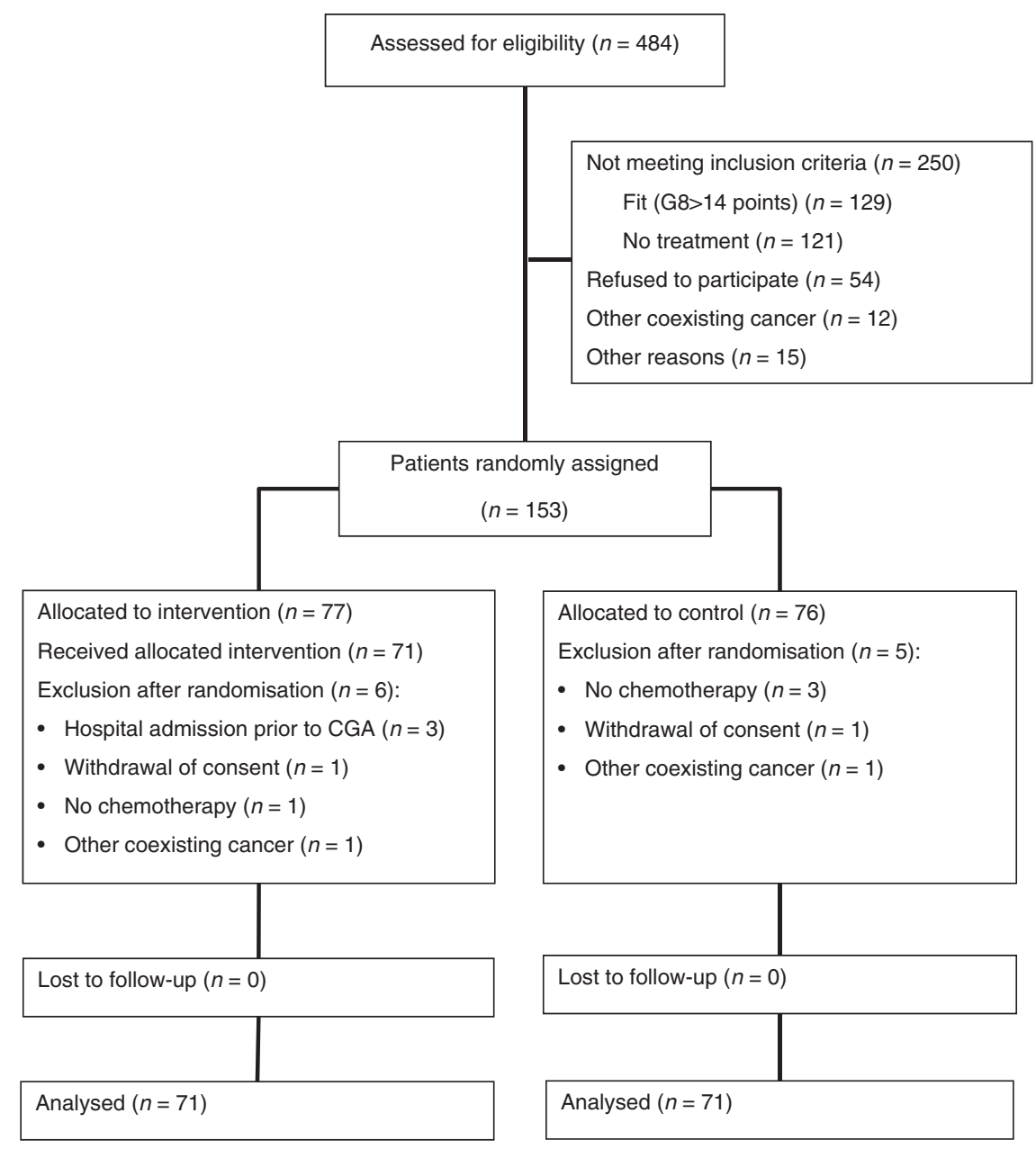

Fig. 1 Screening and inclusion in the GERICO study. Totally 484 patients were assessed and 153 patients were found eligeble for the study. 
Table 2. Baseline characteristics.

\begin{tabular}{|c|c|c|c|}
\hline Characteristics & & $\begin{array}{l}\text { Intervention } \\
\text { group, } N=71, \\
n(\%)\end{array}$ & $\begin{array}{l}\text { Control group, } \\
N=71, n(\%)\end{array}$ \\
\hline Age & Median (range) & $75(70-85)$ & 75 (70-88) \\
\hline \multirow[t]{2}{*}{ Sex } & Men & $43(61)$ & $38(54)$ \\
\hline & Women & $28(39)$ & $33(46)$ \\
\hline \multirow[t]{3}{*}{ PS } & 0 & $32(45)$ & $34(48)$ \\
\hline & 1 & $32(45)$ & $32(45)$ \\
\hline & $\geq 2$ & $7(10)$ & $5(7.0)$ \\
\hline \multirow[t]{2}{*}{ Civil status } & Single & $26(37)$ & $22(31)$ \\
\hline & Living together & $45(63)$ & $49(69)$ \\
\hline BMI & Median (range) & $25(16.8-37.2)$ & $23.3(16.5-33.6)$ \\
\hline Comorbidity & $0-4$ & $11(15)$ & $20(28)$ \\
\hline \multirow[t]{2}{*}{ CIRS-G score } & $5-7$ & $31(44)$ & $26(37)$ \\
\hline & $\geq 8$ & $29(41)$ & $25(35)$ \\
\hline G8 score & Median (range) & $12(7-14)$ & $12(6-14)$ \\
\hline \multirow{4}{*}{$\begin{array}{l}\text { Number of } \\
\text { medications }\end{array}$} & 0 & $2(3)$ & $6(8.4)$ \\
\hline & $1-3$ & $33(47)$ & $24(34)$ \\
\hline & $4-5$ & $19(28)$ & $22(31)$ \\
\hline & $6+$ & $17(24)$ & $19(27)$ \\
\hline \multirow[t]{4}{*}{ Treatment setting } & Adjuvant & $40(56)$ & $37(52)$ \\
\hline & Palliative & $22(31)$ & $22(31)$ \\
\hline & Downstaging & $7(10)$ & $8(11)$ \\
\hline & $\begin{array}{l}\text { Adjuvant after } \\
\text { metastatic } \\
\text { surgery }\end{array}$ & $2(3)$ & $4(5.6)$ \\
\hline \multirow[t]{2}{*}{ Start dose } & Full & $27(38)$ & $30(42)$ \\
\hline & $\begin{array}{l}\text { Primary dose } \\
\text { reduction }\end{array}$ & $44(62)$ & $41(58)$ \\
\hline \multirow[t]{3}{*}{ Tumour location } & Right colon & $32(45)$ & $31(44)$ \\
\hline & Left colon & $25(35)$ & $29(41)$ \\
\hline & Rectum & $14(20)$ & $11(16)$ \\
\hline \multirow{2}{*}{$\begin{array}{l}\text { CT regimen length } \\
\text { adjuvant setting }\end{array}$} & 3 months & $0(0)$ & $3(8)$ \\
\hline & 6 months & $4(100)$ & $34(92)$ \\
\hline \multirow[t]{3}{*}{$\begin{array}{l}\mathrm{CT} \text { regimen } \\
\text { (all patients) }\end{array}$} & $\begin{array}{l}\text { Capecitabine/5- } \\
\text { FU }\end{array}$ & $21(29.6)$ & $26(37)$ \\
\hline & Capeox/Folfox & $35(49.3)$ & $23(32)$ \\
\hline & Capiri/Folfiri & $15(21.1)$ & $22(31)$ \\
\hline $\mathrm{CT}$ regimen & $\begin{array}{l}\text { Capecitabine/5- } \\
\text { FU }\end{array}$ & $15(37.5)$ & $19(51)$ \\
\hline Adjuvant setting & Capeox/Folfox & $25(62.5)$ & $18(49)$ \\
\hline $\mathrm{CT}$ regimen & $\begin{array}{l}\text { Capecitabine/5- } \\
\text { FU }\end{array}$ & $6(27.3)$ & $5(23)$ \\
\hline \multirow[t]{2}{*}{ Palliative setting } & Capeox/Folfox & $4(18.2)$ & $2(9.1)$ \\
\hline & Capiri/Folfiri & $12(54.5)$ & $15(68)$ \\
\hline \multirow[t]{3}{*}{ MSI } & MSI stable & $56(79)$ & $57(80)$ \\
\hline & MSI unstable & $9(13)$ & $11(16)$ \\
\hline & Not known & $6(8)$ & $3(4.2)$ \\
\hline \multirow[t]{3}{*}{ KRAS status } & Mutation & $39(55)$ & $26(37)$ \\
\hline & No mutation & $28(40)$ & $44(62)$ \\
\hline & Not known & $4(6)$ & $1(1)$ \\
\hline \multirow[t]{3}{*}{ NRAS status } & Mutation & $3(4)$ & $4(5.6)$ \\
\hline & No mutation & $58(82)$ & $52(73)$ \\
\hline & Not known & $10(14)$ & $15(21)$ \\
\hline \multirow[t]{3}{*}{ BRAF status } & Mutation & $16(23)$ & $12(17)$ \\
\hline & No mutation & $45(63)$ & $44(62)$ \\
\hline & Not known & $10(14)$ & $15(21)$ \\
\hline
\end{tabular}

$B M I$ body mass index, $C T$ chemotherapy, MSI microsatellite instability, PS ECOG performance status.
Prognosis

The median follow-up time was 27 months (1-65 months). There was no difference between intervention and control patients in prognosis, DFS (adjuvant subgroup $(n=77), \mathrm{HR}=1.60,95 \%$ $\mathrm{Cl} 0.75-3.41)$, PFS (palliative subgroup $(n=44), \mathrm{HR}=0.91,95 \%$ $\mathrm{Cl} 0.48-1.71)$ or in OS (all patients $(n=142), \mathrm{HR}=1.13,95 \% \mathrm{Cl}$ $0.68-1.87)$ and CRC-related mortality (all patients $(n=142), \mathrm{HR}=$ 0.98, 95\% Cl 0.56-1.72) (Supplementary Fig. S1) (for intention-totreat analyses, see Kaplan-Meier plots (Supplementary Fig. S2)).

\section{DISCUSSION}

Among vulnerable, older patients undergoing chemotherapy for stage II-IV CRC, we found that patients receiving CGA-based interventions were more likely to complete scheduled chemotherapy than patients receiving standard care. Furthermore, patients in the intervention group with CGA-based interventions were less likely to experience dose reductions and more patients received full-dose chemotherapy in all cycles, especially in the adjuvant group. This study is one of the first RCTs evaluating the effect of the geriatric intervention on chemotherapy completion rates in vulnerable, older people, a group of patients often underrepresented in clinical trials. ${ }^{42}$ Our findings are in line with a recent RCT by Kalsi et al. investigating the impact of the geriatric intervention on chemotherapy tolerance in 46 older patients with cancer. ${ }^{43}$ They found that patients receiving CGA were more likely to complete planned chemotherapy. The power calculation for this study was based on historical numbers of completion rates for patients above 70 years, which was $~ 50 \%$. However, such numbers for frail or vulnerable older patients and a possible effect of CGA-based interventions were not to be found, as those studies had not yet been performed. Completion rates differed by only $17 \%$, however, this constitutes a $60 \%$ relative completion improvement, achieved by a harmless intervention, by which the findings are still of clinical importance.

In this study, we found a relatively low rate of grade $3+$ adverse events $(28-39 \%)$, with no significant difference in line with Kalsi et al. who found grade $3+$ toxicity rates of $43 \%$ in the intervention group and $52 \%$ among controls. In the larger-cluster RCT by Mohile et al. $(n=557)^{44}$ and the GAIN study $(n=600)^{45}$, geriatric interventions significantly reduced the generally higher rates of grade $3+$ toxicity from 60 to $50 \%$. We found that the QoL domain mobility and burden of illness improved after the geriatric intervention. The changes in QoL were small but were likely to be clinically important for patients according to Crosby et al. ${ }^{46}$ and Norman et al. ${ }^{47}$ who suggested a change of 0.2 and 0.5 standard deviations, respectively, as a useful threshold for discriminating minimal clinically important differences in changes in QoL. Snyder et al. reported on only minimal changes in EORTC-C30 scores for patients who simultaneously reported increased need of supportive care. ${ }^{48}$ However, QoL analyses are connected with uncertainties related to multiple testing and no domains were pre-defined as the main point of interest in the present study. Furthermore, minimal clinically important differences for ELD-14 have not been reported or defined, and this is why the findings should be interpreted with caution. ${ }^{49}$ On the other hand, the present results are in line with the INTEGRATE pilot study; geriatric intervention was also found to increase physical function and several other QoL domains compared with patients receiving usual care. ${ }^{50}$

In this study, reduced start doses were given to a considerably large proportion of all patients, due to concerns of toxicity. However, there was no difference between the intervention and control group, which is why this is unlikely to have had an impact on the results. It is unclear whether older patients should receive the highest possible dose of chemotherapy or reduced doses. High-dose intensities of chemotherapy have been associated with longer survival and decreased cancer mortality in patients with 
Table 3. Outcomes: chemotherapy received, dose reduction and delays.

\begin{tabular}{|c|c|c|c|c|c|c|c|c|c|}
\hline \multirow[t]{2}{*}{ Variable } & \multicolumn{3}{|c|}{ All patients, $N=142$} & \multicolumn{3}{|c|}{ Adjuvant setting, $N=77$} & \multicolumn{3}{|c|}{ Palliative setting, $N=44$} \\
\hline & $\mathrm{I} N=71, n(\%)$ & $\begin{array}{l}C N=71 \\
n(\%)\end{array}$ & $P$ & $I N=40, n(\%)$ & $\begin{array}{l}C N=37 \\
n(\%)\end{array}$ & $P$ & $\mathrm{I} N=22, n(\%)$ & $C N=22, n(\%)$ & $P$ \\
\hline $\begin{array}{l}\text { Completed planned treatment (primary } \\
\text { endpoint) initial dose in all planned cycles }\end{array}$ & $32(45)$ & $20(28)$ & 0.0366 & $20(50)$ & $8(22)$ & 0.0097 & $7(32)$ & $8(36)$ & 0.751 \\
\hline Reduced start dose & $44(62)$ & $41(58)$ & 0.732 & $23(58)$ & $16(43)$ & 0.211 & $15(68)$ & $19(86)$ & 0.150 \\
\hline $\begin{array}{l}\text { Reduction of chemotherapy during } \\
\text { treatment }\end{array}$ & $20(28)$ & $32(45)$ & 0.037 & $10(25)$ & $21(57)$ & 0.005 & $8(36)$ & $7(32)$ & 0.750 \\
\hline Treatment delay & $25(35)$ & $24(34)$ & 0.860 & $8(20)$ & $15(41)$ & 0.049 & $13(59)$ & $6(27)$ & 0.033 \\
\hline Received initial dose in all given cycles & $46(65)$ & $30(42)$ & 0.007 & $25(63)$ & $11(30)$ & 0.004 & $14(64)$ & $12(59)$ & 0.540 \\
\hline \multirow[t]{2}{*}{ Received all planned cycles } & $41(58)$ & $39(55)$ & 0.735 & $26(65)$ & $21(57)$ & 0.459 & $10(45)$ & $11(50)$ & 0.763 \\
\hline & \multicolumn{2}{|l|}{ Median (range) } & $P$ & \multicolumn{2}{|l|}{ Median (range) } & $P$ & \multicolumn{2}{|l|}{ Median (range) } & $P$ \\
\hline Dose intensity: capecitabine/5-FU (\%) & $84(35-117)$ & $89(11-117)$ & 0.724 & $89(67-117)$ & $95(47-117)$ & 0.662 & $93(35-112)$ & $75(11-100)$ & 0.343 \\
\hline Dose intensity: oxaliplatin (\%) & $75(22-169)$ & $87(31-130)$ & 0.134 & $80(22-169)$ & $87(31-92)$ & 0.304 & $78(49-103)$ & $76(76-76)$ & 1.000 \\
\hline Dose intensity: irinotecan (\%) & $65(27-116)$ & $66(4-110)$ & 0.883 & - & - & - & $67(27-116)$ & $63(4-104)$ & 0.240 \\
\hline $\begin{array}{l}\% \text { of planned cycles received capecitabine/ } \\
5-\mathrm{FU}\end{array}$ & $100(8-100)$ & $100(8-100)$ & NA & $100(8-100)$ & $100(8-100)$ & NA & $89(13-100)$ & $92(13-100)$ & 0.763 \\
\hline$\%$ of planned cycles received oxaliplatin & $58(8-100)$ & $63(8-100)$ & 0.825 & $50(8-100)$ & $50(8-100)$ & 0.888 & $89(25-100)$ & $100(100-100)$ & 1.000 \\
\hline$\%$ of planned cycles received irinotecan & $93(60-100)$ & $96(25-100)$ & 0.751 & - & - & - & $91(60-100)$ & $90(25-100)$ & 1.000 \\
\hline Duration of chemotherapy (weeks) & $22.1(0.3-43)$ & $20.1(0.1-53)$ & 0.905 & $22.6(0.3-27)$ & $22.4(0.3-29)$ & 0.855 & $17.2(0.3-43)$ & $21.6(0.1-52)$ & 0.675 \\
\hline
\end{tabular}

I intervention, C control, 5-FU 5-flourouracil.

Bold values indicate significant differences between the intervention and control group.

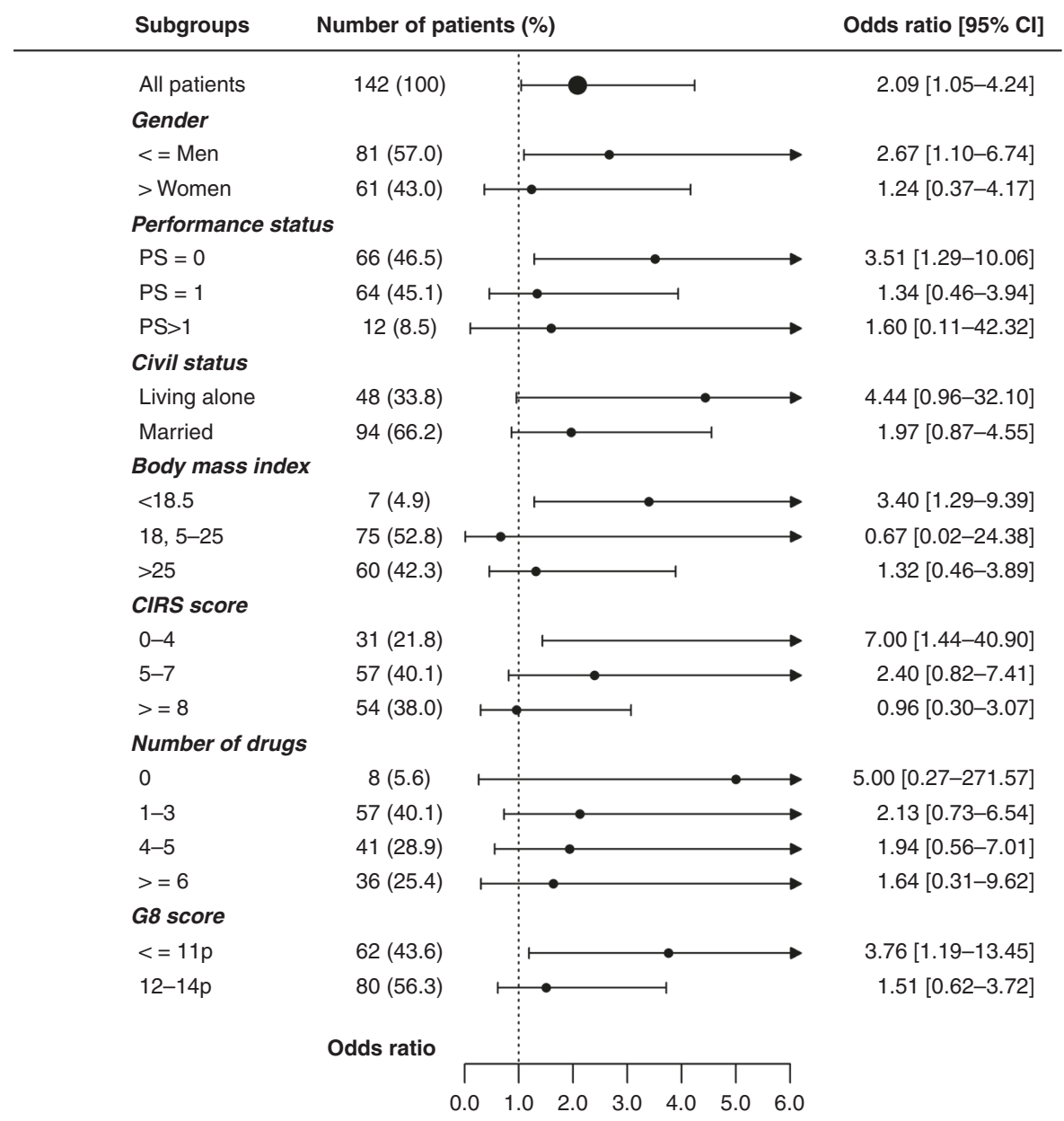

Favours control Favours intervention

Fig. 2 Association between baseline characteristics and completion of planned chemotherapy. CIRS Critical IIIness Rating Scale, PS performance status. 


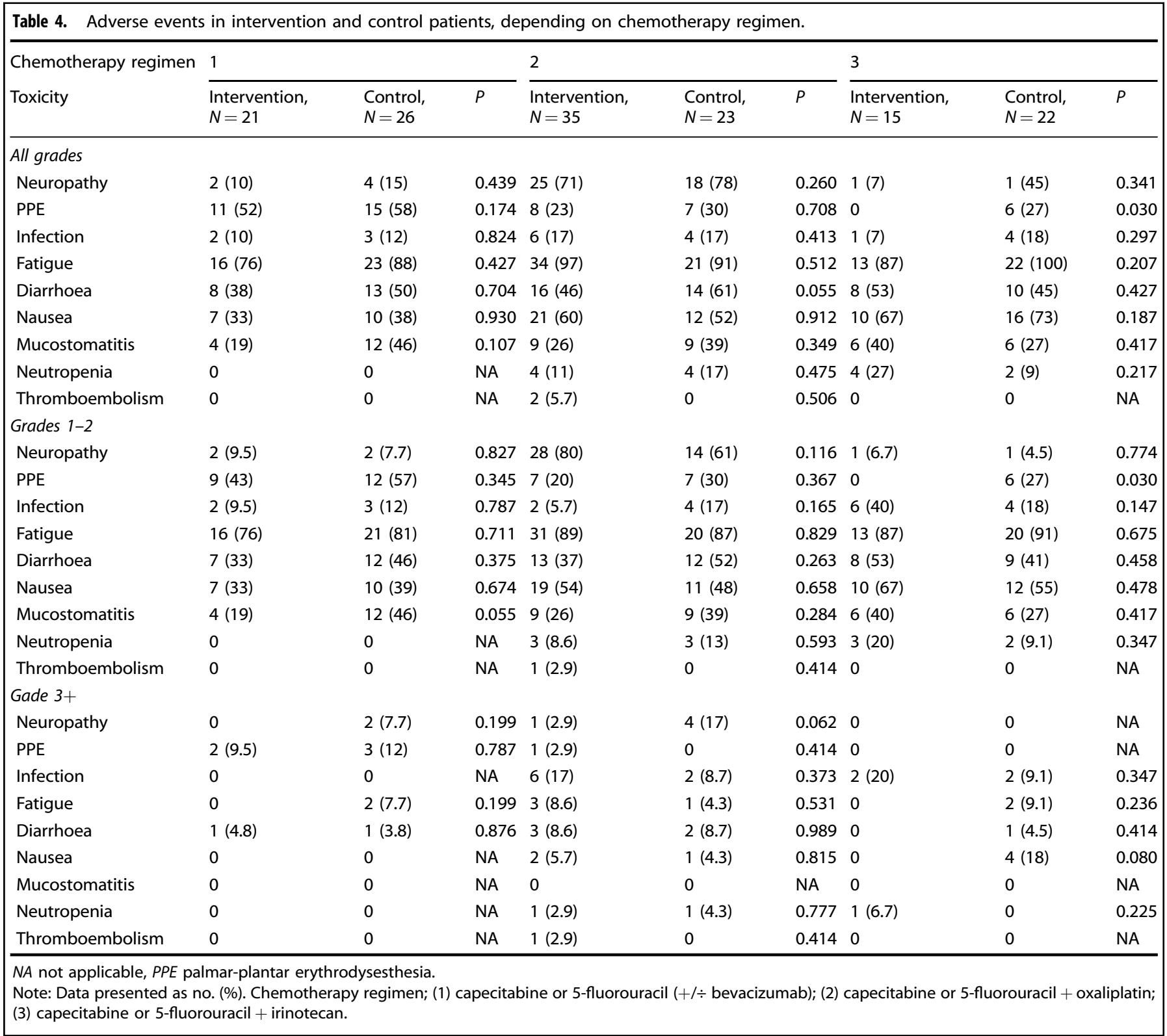

metastatic CRC. ${ }^{51}$ However, chemotherapy and toxicity risk must be carefully balanced, to avoid over- and undertreatment and thereby retain the functional capacity and QoL, possibly better done if integrating geriatric domains before treatment decisions. ${ }^{52}$

In the present RCT, all patients did not accept some of the offered interventions. Thus, a study design where all patients had received exercise and nutritional therapy might have led to more significant results. There seemed to be a difference in patients' willingness to undertake interventions, most frequently due to loss of energy and not wanting more hospital appointments; the patients treated with adjuvant chemotherapy were more likely to accept the suggested interventions. This may explain why the positive results were more prominent among patients in the adjuvant setting. The risk of malnutrition was seen in the majority of patients, which is known to be associated with poor survival and decreased treatment completion in cancer patients. ${ }^{53,54}$ Not all patients at risk accepted dietitian referral and several controls were referred to the dietitian, which may have had an impact on the results.
The exercise was effective in the intervention group. Strength and physical capacity improved significantly in all four tests, which is of clinical importance. ${ }^{40}$ The CST mean improvement was three repetitions, which is known to be a clinically important difference in frail older patients. ${ }^{55}$ We found less subjective feelings of physical decline in the intervention group, most marked in the palliative group. Early rehabilitation is recommended to regain or maintain functional status and increase tolerance to cancer treatment. $^{56}$

None of the patients performed below cut-off in cognitive screening. Most patients were well-educated and MMSE might not be sensitive enough to detect mild cognitive impairments in patients with high cognitive function. ${ }^{57}$ Patients with clear signs of dementia were not offered chemotherapy and therefore not screened for this study. Psychological screening detected possible depression in only $6 \%$, which is lower than that seen in previous data, suggesting depressive symptoms in $\sim 30 \%$ of older patients with cancer. ${ }^{58}$ Our study population was generally independent. However, functional decline and the need for social services in 
the treatment trajectory should be assessed, especially among patients in the palliative setting.

The limitations include the single-centre design, and that the geriatric assessments were performed by a geriatrician and not a multidisciplinary team. Due to ethical considerations, no geriatric baseline measures, including weight loss and physical decline, were applied to the control group; thus, no comparisons could be made regarding CGA. Due to lower recruitment rates than expected, the inclusion criteria were broadened after 1 year, making the study population more heterogeneous. Further limitations include lack of predefined QoL domains of interest, in combination with the non-patient-centred primary endpoint. Treatment aims and goals are likely to be different in adjuvant and palliative treatment settings, where maintenance of physical capacity or change in a QoL domain might have been more patient-relevant outcomes, especially among palliative patients.

During the recruitment period, international guidelines for adjuvant treatment of CRC patients changed and the duration was shortened from 6 to 3 months for some patients, ${ }^{15}$ which was not included in the randomisation strategy. Only patients in the control group were coincidentally scheduled for the more manageable 3 months' treatment. Nevertheless, more patients in the intervention group completed adjuvant chemotherapy.

Our study included vulnerable patients, but not all patients needed any type of intervention, and for patients with G8 score $\leq 11$, geriatric interventions were especially beneficial. Patients who were assessed too frail for chemotherapy and therefore not included in our study might have had an even greater need of CGA. Future research should focus on patient-centred outcomes as QoL or functional status, also in patients deemed too frail for chemotherapy and whether CGA-based interventions can improve health status and reassessment for active treatment.

Finally, the follow-up time was short, and our trial was not powered (sample size too small) to evaluate secondary survival outcomes, and we found no difference in DFS, PFS and OS between the intervention and control groups.

In conclusion, this RCT demonstrates the benefit of geriatric interventions for older, vulnerable patients with CRC. Geriatric interventions compared with standard care increased the number of older, vulnerable patients with CRC completing scheduled adjuvant chemotherapy with no increase in adverse events. Geriatric interventions may also improve the burden of illness and mobility; however, larger studies are needed to confirm the beneficial findings. Furthermore, patients in the palliative setting reported less functional decline after geriatric interventions than patients receiving standard care. Exercise significantly improved muscle strength and physical capacity. Geriatric interventions, including supervised exercise, can be recommended to improve treatment outcomes in older, vulnerable patients receiving chemotherapy for CRC.

\section{ACKNOWLEDGEMENTS}

We thank all patients and their caregivers for participating in this trial. We also thank all co-investigators and people who have helped design and prepare this trial, in particular Hanne Elkjær Andersen Copenhagen University Hospital Glostrup, and Knud Mejer Nelausen (dead after entering the research group), Susan Theile, Hanne Michelsen, Charlotte Toft, Jakob Hagen Vasehus Schou, Svend-Erik Nielsen, Hanne Forbech Skall, Anne-Mette Ragle, Carsten Bogh Juhl, Anders Vinther, and Tina Munk, Herlev and Gentofte Hospital, Copenhagen University Hospital, and Fahime Andersen, Nordsjællands Hospital.

\section{AUTHOR CONTRIBUTIONS}

Conception and design: C.L., D.N., J.S.J., K.K.V. and F.R. Collection and assembly of the data: C.L., K.K.V., A.P.O., P.B., T.G.D. and J.S.J. Data analysis and interpretation: C.L., M.S., D.N., J.S.J. and K.K.V. Paper writing: C.L., K.K.V., A.P.O., P.B., M.S., T.G.D., F.R., J.S.J. and
D.N. Final approval of the paper: C.L., K.K.V., A.P.O., P.B., M.S., T.G.D., F.R., J.S.J. and D.N. Accountable for all aspects of the work: C.L., K.K.V., A.P.O., P.B., M.S., T.G.D., F.R., J.S.J. and D.N.

\section{ADDITIONAL INFORMATION}

Ethics approval and consent to participate The study was conducted in accordance with the Declaration of Helsinki and the International Conference on Harmonization Good Clinical Practice Guideline. The study was approved by the local ethics committee (Capital Region, reference number: H-7-2014-015) and the Danish Data Protection Agency, reference number: 03339, HEH-2014-112. Written informed consent was obtained from all enrolled patients.

Consent to publish Not applicable.

Data availability For data supporting the results of this study, contact the corresponding author.

Competing interests The authors declare no competing interests.

Funding information This work was supported by Aage and Johanne Louis-Hansen Foundation, Beckett Foundation, Danielsen Foundation, Danish Cancer Society, Doctor Sofus Carl Emil Friis and wife Olga Doris Friis Scholarship, Foundation for Clinical Cancer Research, Hede Nielsen Foundation and Velux Foundation. Grant numbers not applicable.

Supplementary information The online version contains supplementary material available at https://doi.org/10.1038/s41416-021-01367-0.

Publisher's note Springer Nature remains neutral with regard to jurisdictional claims in published maps and institutional affiliations.

\section{REFERENCES}

1. Mohile, S. G., Dale, W., Somerfield, M. R., Schonberg, M. A., Boyd, C. M., Burhenn, P. $S$. et al. Practical assessment and management of vulnerabilities in older patients receiving chemotherapy: ASCO guideline for geriatric oncology. J. Clin. Oncol. 36, 2326-2347 (2018).

2. Siegel, R. L., Miller, K. D. \& Jemal, A. Cancer statistics, 2020. CA Cancer J. Clin. 70, 7-30 (2020).

3. Christensen, K., Doblhammer, G., Rau, R. \& Vaupel, J. W. Ageing populations: the challenges ahead. Lancet 374, 1196-1208 (2009).

4. Papamichael, D., Audisio, R. A., Glimelius, B., de Gramont, A., Glynne-Jones, R., Haller, D. et al. Treatment of colorectal cancer in older patients: International Society of Geriatric Oncology (SIOG) consensus recommendations 2013. Ann. Oncol. 26, 463-476 (2015).

5. Hurria, A., Togawa, K., Mohile, S. G., Owusu, C., Klepin, H. D., Gross, C. P. et al. Predicting chemotherapy toxicity in older adults with cancer: a prospective multicenter study. J. Clin. Oncol. 29, 3457-3465 (2011).

6. Kordatou, Z., Kountourakis, P. \& Papamichael, D. Treatment of older patients with colorectal cancer: a perspective review. Ther. Adv. Med. Oncol. 6, 128-140 (2014).

7. Kim, J. H. Chemotherapy for colorectal cancer in the elderly. World J. Gastroenterol. 21, 5158-5166 (2015).

8. Power, D. G. \& Lichtman, S. M. Chemotherapy for the elderly patient with colorectal cancer. Cancer J. 16, 241-252 (2010).

9. Quaglia, A., Tavilla, A., Shack, L., Brenner, H., Janssen-Heijnen, M., Allemani, C. et al. The cancer survival gap between elderly and middle-aged patients in Europe is widening. Eur. J. Cancer 45, 1006-1016 (2009).

10. Winther, S. B., Baatrup, G., Pfeiffer, P. \& Qvortrup, C. Trends in colorectal cancer in the elderly in Denmark, 1980-2012. Acta Oncol. 55, 29-39 (2016).

11. Gill, S., Loprinzi, C. L., Sargent, D. J., Thome, S. D., Alberts, S. R., Haller, D. G. et al. Pooled analysis of fluorouracil-based adjuvant therapy for stage II and III colon cancer: who benefits and by how much? J. Clin. Oncol. 22, 1797-1806 (2004).

12. Gray, R., Barnwell, J., McConkey, C., Hills, R. K., Williams, N. S. \& Kerr, D. J. Adjuvant chemotherapy versus observation in patients with colorectal cancer: a randomised study. Lancet 370, 2020-2029 (2007).

13. Twelves, C., Wong, A., Nowacki, M. P., Abt, M., Burris, H. 3rd, Carrato, A. et al. Capecitabine as adjuvant treatment for stage III colon cancer. N. Engl. J. Med. 352, 2696-2704 (2005) 
14. Schmoll, H. J., Twelves, C., Sun, W., O'Connell, M. J., Cartwright, T., McKenna, E. et al. Effect of adjuvant capecitabine or fluorouracil, with or without oxaliplatin, on survival outcomes in stage III colon cancer and the effect of oxaliplatin on post-relapse survival: a pooled analysis of individual patient data from four randomised controlled trials. Lancet Oncol. 15, 1481-1492 (2014).

15. Grothey, A., Sobrero, A. F., Shields, A. F., Yoshino, T., Paul, J., Taieb, J. et al. Duration of adjuvant chemotherapy for stage III colon cancer. N. Engl. J. Med. 378, 1177-1188 (2018).

16. Petersen, S. H., Harling, H., Kirkeby, L. T., Wille-Jorgensen, P. \& Mocellin, S. Postoperative adjuvant chemotherapy in rectal cancer operated for cure. Cochrane Database Syst. Rev. CD004078 (2012).

17. Sargent, D. J., Goldberg, R. M., Jacobson, S. D., Macdonald, J. S., Labianca, R., Haller, D. G. et al. A pooled analysis of adjuvant chemotherapy for resected colon cancer in elderly patients. N. Engl. J. Med. 345, 1091-1097 (2001).

18. Sanoff, H. K., Carpenter, W. R., Sturmer, T., Goldberg, R. M., Martin, C. F., Fine, J. P. et al. Effect of adjuvant chemotherapy on survival of patients with stage III colon cancer diagnosed after age 75 years. J. Clin. Oncol. 30, 2624-2634 (2012).

19. Hoeben, K. W., van Steenbergen, L. N., van de Wouw, A. J., Rutten, H. J., van Spronsen, D. J. \& Janssen-Heijnen, M. L. Treatment and complications in elderly stage III colon cancer patients in the Netherlands. Ann. Oncol. 24, 974-979 (2013).

20. Iwashyna, T. J. \& Lamont, E. B. Effectiveness of adjuvant fluorouracil in clinical practice: a population-based cohort study of elderly patients with stage III colon cancer. J. Clin. Oncol. 20, 3992-3998 (2002).

21. Sorbye, H., Cvancarova, M., Qvortrup, C., Pfeiffer, P. \& Glimelius, B. Age-dependent improvement in median and long-term survival in unselected population-based Nordic registries of patients with synchronous metastatic colorectal cancer. Ann. Oncol. 24, 2354-2360 (2013).

22. Wildiers, H., Heeren, P., Puts, M., Topinkova, E., Janssen-Heijnen, M. L., Extermann, M. et al. International Society of Geriatric Oncology consensus on geriatric assessment in older patients with cancer. J. Clin. Oncol. 32, 2595-2603 (2014).

23. Mohile, S. G., Velarde, C., Hurria, A., Magnuson, A., Lowenstein, L., Pandya, C. et al. Geriatric assessment-guided care processes for older adults: a Delphi consensus of geriatric oncology experts. J. Natl Compr. Canc Netw. 13, 1120-1130 (2015).

24. Ellis, G., Whitehead, M. A., Robinson, D., O'Neill, D. \& Langhorne, P. Comprehensive geriatric assessment for older adults admitted to hospital: meta-analysis of randomised controlled trials. BMJ 343, d6553 (2011).

25. Extermann, M. \& Hurria, A. Comprehensive geriatric assessment for older patients with cancer. J. Clin. Oncol. 25, 1824-1831 (2007).

26. Wildes, T. M., Ruwe, A. P., Fournier, C., Gao, F., Carson, K. R., Piccirillo, J. F. et al. Geriatric assessment is associated with completion of chemotherapy, toxicity, and survival in older adults with cancer. J. Geriatr. Oncol. 4, 227-234 (2013).

27. Aparicio, T., Jouve, J. L., Teillet, L., Gargot, D., Subtil, F., Le Brun-Ly, V. et al. Geriatric factors predict chemotherapy feasibility: ancillary results of FFCD 2001-02 phase III study in first-line chemotherapy for metastatic colorectal cancer in elderly patients. J. Clin. Oncol. 31, 1464-1470 (2013).

28. Li, D., Soto-Perez-de-Celis, E. \& Hurria, A. Geriatric assessment and tools for predicting treatment toxicity in older adults with cancer. Cancer J. 23, 206-210 (2017).

29. Ommundsen, N., Wyller, T. B., Nesbakken, A., Jordhoy, M. S., Bakka, A., Skovlund, E. et al. Frailty is an independent predictor of survival in older patients with colorectal cancer. Oncologist 19, 1268-1275 (2014).

30. Hamaker, M. E., Te Molder, M., Thielen, N., van Munster, B. C., Schiphorst, A. H. \& van Huis, L. H. The effect of a geriatric evaluation on treatment decisions and outcome for older cancer patients-a systematic review. J. Geriatr. Oncol. 9, 430-440 (2018).

31. Decoster, L., Van Puyvelde, K., Mohile, S., Wedding, U., Basso, U., Colloca, G. et al. Screening tools for multidimensional health problems warranting a geriatric assessment in older cancer patients: an update on SIOG recommendationst. Ann. Oncol. 26, 288-300 (2015).

32. van Walree, I. C., Scheepers, E., van Huis-Tanja, L., Emmelot-Vonk, M. H., Bellera, C., Soubeyran, P. et al. A systematic review on the association of the G8 with geriatric assessment, prognosis and course of treatment in older patients with cancer. J. Geriatr. Oncol. 10, 847-858 (2019).

33. Leo, S., Accettura, C., Gnoni, A., Licchetta, A., Giampaglia, M., Mauro, A. et al. Systemic treatment of gastrointestinal cancer in elderly patients. J. Gastrointest. Cancer 44, 22-32 (2013).

34. Lund, C. M., Vistisen, K. K., Dehlendorff, C., Ronholt, F., Johansen, J. S. \& Nielsen, D. L. The effect of geriatric intervention in frail elderly patients receiving chemotherapy for colorectal cancer: a randomized trial (GERICO). BMC Cancer 17, 448 (2017).

35. Oken, M. M., Creech, R. H., Tormey, D. C., Horton, J., Davis, T. E., McFadden, E. T. et al. Toxicity and response criteria of the Eastern Cooperative Oncology Group. Am. J. Clin. Oncol. 5, 649-655 (1982).
36. Bellera, C. A., Rainfray, M., Mathoulin-Pelissier, S., Mertens, C., Delva, F., Fonck, M. et al. Screening older cancer patients: first evaluation of the G-8 geriatric screening tool. Ann. Oncol. 23, 2166-2172 (2012).

37. Aaronson, N. K., Ahmedzai, S., Bergman, B., Bullinger, M., Cull, A., Duez, N. J., Filiberti, A. et al. The European Organization for Research and Treatment of Cancer QLQ-C30: a quality-of-life instrument for use in international clinical trials in oncology. J. Natl Cancer Inst. 85, 365-376 (1993).

38. Wheelwright, S., Darlington, A. S., Fitzsimmons, D., Fayers, P., Arraras, J. I., Bonnetain, $F$. et al. International validation of the EORTC QLQ-ELD14 questionnaire for assessment of health-related quality of life elderly patients with cancer. Br. J. Cancer 109, 852-858 (2013).

39. RStudio Team, RStudio: Integrated Development for R. RStudio, Inc., Boston, MA. http://www.rstudio.com/ (2015).

40. Lipsey, M. W. \& Wilson, D. B. The efficacy of psychological, educational, and behavioral treatment. Confirmation from meta-analysis. Am. Psychol. 48, 1181-1209 (1993).

41. Martin, L., Senesse, P., Gioulbasanis, I., Antoun, S., Bozzetti, F., Deans, C. et al. Diagnostic criteria for the classification of cancer-associated weight loss. J. Clin. Oncol. 33, 90-99 (2015).

42. Scher, K. S. \& Hurria, A. Under-representation of older adults in cancer registration trials: known problem, little progress. J. Clin. Oncol. 30, 2036-2038 (2012).

43. Kalsi, T., Babic-Illman, G., Ross, P. J., Maisey, N. R., Hughes, S., Fields, P. et al. The impact of comprehensive geriatric assessment interventions on tolerance to chemotherapy in older people. Br. J. Cancer 112, 1435-1444 (2015).

44. Mohile, S. G., Refaat, M. M., Culakova, E., Xu, H., Loh, K. P., Magnuson, A. et al. A gertiatric assessment (GA) intervention to reduce treatment toxicity in older patients with advanced cancer: a University of Rochester Cancer Center $\mathrm{NCl}$ Community Pncology Research Program cluster randomized controlled trial (CRCT). 2020 ASCO Virtual Scientific Program (Abstract 12009) (2020).

45. Li, D., Sun, C. L., Kim, H., Chung, V., Koczywas, M., Fakih, M. et al. Geriatric assessment-driven intervention (GAIN) on chemotherapy toxicity in older adults with cancer: a randomized controlled trial. 2020 ASCO Virtual Scientific Program (Abstract 12010) (2020).

46. Crosby, R. D., Kolotkin, R. L. \& Williams, G. R. Defining clinically meaningful change in health-related quality of life. J. Clin. Epidemiol. 56, 395-407 (2003).

47. Norman, G. R., Sloan, J. A. \& Wyrwich, K. W. Interpretation of changes in healthrelated quality of life: the remarkable universality of half a standard deviation. Med. Care 41, 582-592 (2003).

48. Snyder, C. F., Blackford, A. L., Sussman, J., Bainbridge, D., Howell, D., Seow, H. Y. et al. Identifying changes in scores on the EORTC-QLQ-C30 representing a change in patients' supportive care needs. Qual. Life Res. 24, 1207-1216 (2015).

49. Efficace, F., Fayers, P., Pusic, A., Cemal, Y., Yanagawa, J., Jacobs, M. et al. Quality of patient-reported outcome reporting across cancer randomized controlled trials according to the CONSORT patient-reported outcome extension: a pooled analysis of 557 trials. Cancer 121, 3335-3342 (2015).

50. Soo, W. K., King, M., Pope, A., Parente, P. \& Darzins, P. Integrated geriatric assessment and treatment (INTEGERATE) in older people with cancer planned for systemic anticancer therapy. ASCO Virtuel Scientific Program (Abstract 12011) (2020).

51. Lund, C. M., Vistisen, K. K., Dehlendorff, C., Ronholt, F., Johansen, J. S. \& Nielsen, D. $\mathrm{L}$. Age-dependent differences in first-line chemotherapy in patients with metastatic colorectal cancer: the DISCO study. Acta Oncol. 57, 1445-1454 (2018).

52. DuMontier, C., Loh, K. P., Bain, P. A., Silliman, R. A., Hshieh, T., Abel, G. A. et al. Defining undertreatment and overtreatment in older adults with cancer: a scoping literature review. J. Clin. Oncol. 38, 2558-2569 (2020).

53. Dewys, W. D., Begg, C., Lavin, P. T., Band, P. R., Bennett, J. M., Bertino, J. R. et al. Prognostic effect of weight loss prior to chemotherapy in cancer patients. Eastern Cooperative Oncology Group. Am. J. Med. 69, 491-497 (1980).

54. Hamaker, M. E., Oosterlaan, F., van Huis, L. H., Thielen, N., Vondeling, A. \& van den Bos, F. Nutritional status and interventions for patients with cancer-a systematic review. J. Geriatr. Oncol. https://doi.org/10.1016/j.jgo.2020.06.020 (2020).

55. Wright, A. A., Cook, C. E., Baxter, G. D., Dockerty, J. D. \& Abbott, J. H. A comparison of 3 methodological approaches to defining major clinically important improvement of 4 performance measures in patients with hip osteoarthritis. J. Orthop. Sports Phys. Ther. 41, 319-327 (2011).

56. Stout, N. L., Silver, J. K., Raj, V. S., Rowland, J., Gerber, L., Cheville, A. et al. Toward a national initiative in cancer rehabilitation: recommendations from a subject matter expert group. Arch. Phys. Med. Rehabil. 97, 2006-2015 (2016).

57. Freitas, S., Simoes, M. R., Alves, L. \& Santana, I. The relevance of sociodemographic and health variables on MMSE normative data. Appl. Neuropsychol. Adult 22, 311-319 (2015).

58. Canoui-Poitrine, F., Reinald, N., Laurent, M., Guery, E., Caillet, P., David, J. P. et al. Geriatric assessment findings independently associated with clinical depression in 1092 older patients with cancer: the ELCAPA cohort study. Psychooncology 25, 104-111 (2016). 
The effect of geriatric intervention in frail older patients receiving...

CM Lund et al.

1958

(c) Open Access This article is licensed under a Creative Commons

Attribution 4.0 International License, which permits use, sharing,

adaptation, distribution and reproduction in any medium or format, as long as you give appropriate credit to the original author(s) and the source, provide a link to the Creative

Commons license, and indicate if changes were made. The images or other third party material in this article are included in the article's Creative Commons license, unless indicated otherwise in a credit line to the material. If material is not included in the article's Creative Commons license and your intended use is not permitted by statutory regulation or exceeds the permitted use, you will need to obtain permission directly from the copyright holder. To view a copy of this license, visit http://creativecommons. org/licenses/by/4.0/.

(c) The Author(s) 2021 